DOI: $10.17516 / 2782-2214-0031$

УДК 339.13.017

\title{
METHODOLOGICAL APPROACHES TO ASSESSMENT OF DEVELOPMENT OF THE TRADING SERVICES MARKET TAKING BASED ON DIGITAL TRANSFORMATIONS
}

\author{
Vasily V. Kuimov, Alexandra K. Yakobson* \\ Siberian Federal University, Krasnoyarsk, Russian Federation
}

\begin{abstract}
This article discusses methodological approaches to assessing the development of the trade services market, their advantages and disadvantages, taking into account the current trends in the digitalization of the economy. Based on the existing methods, the authors propose a methodological approach to assessing the development of the trading services market. The main difference of the author's methodology is its complex nature and taking into account the level of development of the digital transformation process in the market, which allows us to identify cause-and-effect relationships between the indicators of the digitalization process and the main processes taking place in the market on the basis of a matrix of expert assessments.

Keywords: trading services market, digitalization, digital transformation of the market, research of the trading services market, assessment of the development of the trading services market.

Citation: Kuimov, V. V., Yakobson, A. K. (2021). Methodological approaches to assessment of development of the trading services market taking based on digital transformations. Trade, service, food industry. Vol. 1(4). Pp. 381-389.

\section{МЕТОДИЧЕСКИЕ ПОДХОДЫ К ОЦЕНКЕ СОСТОЯНИЯ И РАЗВИТИЯ РЫНКА ТОРГОВЫХ УСЛУГ НА ОСНОВЕ ЦИФРОВЫХ ТРАНСФОРМАЦИЙ Василий Васильевич Куимов, Александра Константиновна Якобсон ${ }^{*}$ ФГАОУ ВО «Сибирский федеральный университет», Красноярск, Российская Федерация}

Аннотация. В данной статье рассмотрены методологические подходы к оценке развития рынка торговых услуг, их достоинства и недостатки в свете современных тенденций цифровизации экономики. На основе существующих методик авторы предлагаются собственный подход к такой оценке. Основное отличие представляемой методики состоит в еe комплексном характере и учете уровня цифровой трансформации рынка, что позволяет на базе матрицы экспертных оценок выявить причинно-следственные связи между индикаторами цифровизации и основными процессами, протекающими в современной торговле.

Ключевые слова: рынок торговых услуг, цифровизация, цифровая трансформация рынка, исследование рынка торговых услуг, оценка развития рынка торговых услуг.

Введение. В условиях высокой изменчивости рынка торговых услуг и его стремительного развития необходимо производить мониторинг основных элементов, а также оценивать общие тенденции данной сферы. Методикам по исследованию рынка

(C) Siberian Federal University. All rights reserved

* Corresponding author E-mail address: audis5@bk.ru 
торговых услуг и его отдельных частей со стороны деятельности торговых агентов посвящен внушительный массив научных публикаций, ряд которых лег в основу рассматриваемого подхода.

Материалы и методы. Краткий анализ существующих методик оценки развития рынка представлен в табл. 1.

Таблица 1. Авторские методики оценки рынка торговых услуг и его компонентов Table 1. Author's methods of assessing the market of trade services and its components

\begin{tabular}{|c|c|c|}
\hline Автор и содержание методики & Преимущества & $\begin{array}{c}\text { Недостатки } \\
\text { (ограничения по } \\
\text { использованию) }\end{array}$ \\
\hline $\begin{array}{l}\text { Шнорр Ж. П. Методика идентификации } \\
\text { торговых сетей. Включает в себя } 3 \\
\text { этапа. } \\
1 \text { - целеполагание, постановка задач, } \\
\text { определение принципов, признаков и } \\
\text { показателей, характеризующих торговые } \\
\text { сети. } \\
2 \text {-проверка соответствия признаков } \\
\text { торговых объединений признакам } \\
\text { торговых сетей и бизнес-сетей, } \\
3 \text { - применение комплекса показателей, } \\
\text { соотносимых с принципами деятельности } \\
\text { и статусом торговых сетей, в } \\
\text { определенной последовательности [10] }\end{array}$ & $\begin{array}{l}\text { Данный подход } \\
\text { позволяет } \\
\text { соотносить } \\
\text { торговые сети } \\
\text { между собой и } \\
\text { выявлять их } \\
\text { сильные и слабые } \\
\text { стороны. } \\
\text { Применяя его, } \\
\text { можно определить } \\
\text { место торговой } \\
\text { сети в соответствии } \\
\text { с авторскими } \\
\text { принципами }\end{array}$ & $\begin{array}{l}\text { Слабая } \\
\text { информационная } \\
\text { обеспеченность. } \\
\text { Методика } \\
\text { применима в } \\
\text { рамках одной } \\
\text { торговой сети, так } \\
\text { как большая доля } \\
\text { информации } \\
\text { является } \\
\text { коммерческой } \\
\text { тайной }\end{array}$ \\
\hline $\begin{array}{l}\text { Цивлин А. П. Метод составления } \\
\text { индекса SSI на базе метода численной } \\
\text { оценки. Критериями оценки данного } \\
\text { метода выступают доступность, } \\
\text { целостность, непрерывность. Основа } \\
\text { подхода - системная интегральная } \\
\text { оценка эффективности со взвешенной } \\
\text { полезностью (SSI). Расчет данного } \\
\text { показателя состоит из двух этапов: } \\
\text { нормирование величины и ее } \\
\text { взвешивание. В основе взвешивания } \\
\text { лежит экспертный метод, с помощью } \\
\text { которого ранжируется вес каждого } \\
\text { фактора, влияющего на качество услуги, } \\
\text { и устанавливается взаимозависимость с } \\
\text { нормированной величиной [9] }\end{array}$ & $\begin{array}{l}\text { Отображаемая } \\
\text { методика помогает } \\
\text { выявить недостаток } \\
\text { (избыточность) } \\
\text { точек контакта } \\
\text { цифрового } \\
\text { продукта и клиента }\end{array}$ & $\begin{array}{l}\text { Может } \\
\text { применяться } \\
\text { только к цифровым } \\
\text { видам торговых } \\
\text { услуг. } \\
\text { Узконаправленный } \\
\text { подход, } \\
\text { позволяющий } \\
\text { оценить только } \\
\text { контакт с } \\
\text { клиентом. } \\
\text { Субъективен из-за } \\
\text { использования } \\
\text { экспертного метода }\end{array}$ \\
\hline $\begin{array}{l}\text { Чкалова О. В. Методика оценки } \\
\text { месторасположения торговых центров. } \\
\text { Алгоритм данного метода включает в } \\
\text { себя следующее: } \\
\text { 1. Оценка макрорасположения торговых } \\
\text { центров в разрезе регионов: } \\
\text { - изучение привлекательности регионов } \\
\text { (изучение показателей, характеризующих }\end{array}$ & $\begin{array}{l}\text { Позволяет } \\
\text { определить } \\
\text { наиболее } \\
\text { привлекательную } \\
\text { зону расположения } \\
\text { торговых } \\
\text { предприятий } \\
\text { научным путем }\end{array}$ & $\begin{array}{l}\text { Субъективен, } \\
\text { поскольку основан } \\
\text { на методе } \\
\text { экспертных оценок }\end{array}$ \\
\hline
\end{tabular}




\begin{tabular}{|c|c|c|}
\hline $\begin{array}{l}\text { уровень жизни населения территорий, } \\
\text { уровень обеспеченности населения } \\
\text { торговыми услугами); } \\
\text { - составление карты привлекательности; } \\
\text { - процесс ранжирования регионов; } \\
\text { - выбор наиболее привлекательных } \\
\text { регионов } \\
\text { 2. Оценка микрорасположения } \\
\text { территорий внутри потенциально } \\
\text { привлекательных регионов методом } \\
\text { экспертной оценки [1] }\end{array}$ & & \\
\hline $\begin{array}{l}\text { Терещенко Н. Н. Методика оценки } \\
\text { эффективности деятельности } \\
\text { предприятий розничной торговли. } \\
\text { Данную методику, с позиции автора, } \\
\text { рационально применять в двух } \\
\text { направлениях: с позиции потребителей и } \\
\text { с точки зрения собственников } \\
\text { (администрации) предприятия. В первом } \\
\text { варианте оценивается целесообразность } \\
\text { посещения торгового предприятия } \\
\text { (удовлетворение спроса, удобное } \\
\text { месторасположение); экономичность } \\
\text { (экономия времени, уровень затрат на } \\
\text { приобретение); удовлетворенность } \\
\text { (соотношение цены и качества товаров, } \\
\text { достаточный ассортимент). Второе } \\
\text { направление данной методики оценивают } \\
\text { исходя из критериев целесообразности, } \\
\text { экономичности, результативности [7] }\end{array}$ & $\begin{array}{l}\text { Исследования } \\
\text { деятельности } \\
\text { предприятия с } \\
\text { позиции двух } \\
\text { заинтересованных } \\
\text { групп позволяет } \\
\text { выявить резервы } \\
\text { роста } \\
\text { экономической } \\
\text { эффективности } \\
\text { предприятия }\end{array}$ & $\begin{array}{l}\text { Применение } \\
\text { данного метода } \\
\text { возможно только } \\
\text { на предприятиях } \\
\text { розничной } \\
\text { торговли }\end{array}$ \\
\hline $\begin{array}{l}\text { Куимов В. В., Смоленцева Л. Т. } \\
\text { Функционально-средовой подход в } \\
\text { управлении изменениями на } \\
\text { предприятии. Позволяет управлять } \\
\text { деятельностью предприятия в условиях } \\
\text { функционально-средового } \\
\text { взаимодействия. Анализ проводится в } \\
\text { разрезе конкретной среды: } 1 \text { - внешняя } \\
\text { среда, } 2 \text { - среда взаимодействия, } 3 \text { - } \\
\text { конкурентная среда, } 4 \text { - внутренняя среда } \\
\text { (согласование деятельности всех } \\
\text { подразделений предприятия на } \\
\text { достижение результатов и обеспечение } \\
\text { развития) [3] }\end{array}$ & $\begin{array}{l}\text { Данный метод } \\
\text { позволяет } \\
\text { ориентировать } \\
\text { деятельность всех } \\
\text { подразделений на } \\
\text { решение } \\
\text { поставленной } \\
\text { задачи и системно } \\
\text { контролировать } \\
\text { ход его (решения) } \\
\text { реализации }\end{array}$ & $\begin{array}{l}\text { Трудоемкость } \\
\text { данного метода } \\
\text { определена } \\
\text { обработкой } \\
\text { большого объема } \\
\text { информации и } \\
\text { необходимостью } \\
\text { своевременного } \\
\text { анализа }\end{array}$ \\
\hline $\begin{array}{l}\text { Григорьев Д. А., Суслова Ю. Ю. } \\
\text { Методический подход к изучению } \\
\text { рыночного потенциала и его емкости. } \\
\text { Рыночный потенциал рассматривается в } \\
\text { трех аспектах: как емкостная } \\
\text { характеристика; как математическая }\end{array}$ & $\begin{array}{l}\text { Методика изучения } \\
\text { рыночного } \\
\text { потенциала и его } \\
\text { емкости позволяет } \\
\text { провести } \\
\text { достоверные }\end{array}$ & $\begin{array}{l}\text { Данная методика } \\
\text { является } \\
\text { узконаправленной } \\
\text { и не позволяет } \\
\text { учитывать } \\
\text { специфические }\end{array}$ \\
\hline
\end{tabular}




\begin{tabular}{|c|c|c|}
\hline $\begin{array}{l}\text { составляющая и как социально- } \\
\text { экономическая составляющая. Авторами } \\
\text { предложено изучение рыночного } \\
\text { потенциала и его емкости посредством } \\
\text { логической последовательности ряда } \\
\text { действий: изучения рыночного } \\
\text { потенциала и емкости рынка, а также дан } \\
\text { расчет дополнительного показателя: } \\
\text { оценки совокупной емкости } \\
\text { потребительского рынка (динамики } \\
\text { продажи отдельных товаров за } \\
\text { определенный период времени) [5] }\end{array}$ & $\begin{array}{l}\text { расчеты этих } \\
\text { экономический } \\
\text { категорий, } \\
\text { скорректировать на } \\
\text { их основании } \\
\text { ассортимент } \\
\text { продаваемой } \\
\text { продукции и } \\
\text { актуализировать } \\
\text { сбытовую и } \\
\text { закупочную } \\
\text { деятельность } \\
\text { предприятия }\end{array}$ & $\begin{array}{l}\text { особенности } \\
\text { отдельных товаров } \\
\text { или товарных } \\
\text { групп }\end{array}$ \\
\hline $\begin{array}{l}\text { Марцулевич Д. В. Методика оценки } \\
\text { влияния фактора удобства } \\
\text { использования на удовлетворенность } \\
\text { потребителей интернет-магазина. Для } \\
\text { оценки удобства использования } \\
\text { (юзабилити) автор предлагает изучить } \\
\text { влияние факторов потребительского } \\
\text { опыта на удовлетворенность } \\
\text { потребителей путем анкетного } \\
\text { исследования и выявить ключевые } \\
\text { гипотезы, а также их взаимозависимость } \\
\text { друг от друга [4] }\end{array}$ & $\begin{array}{l}\text { Помогает } \\
\text { достоверно точно } \\
\text { определить } \\
\text { основные факторы } \\
\text { влияющие, на } \\
\text { удовлетворенность } \\
\text { потребителей от } \\
\text { использования } \\
\text { онлайн-сервисов }\end{array}$ & $\begin{array}{l}\text { Требует } \\
\text { достаточной } \\
\text { квалификации и } \\
\text { профессионализма } \\
\text { от специалиста, } \\
\text { отвечающего за } \\
\text { проведение } \\
\text { данного анализа. } \\
\text { Возможно } \\
\text { применение только } \\
\text { при наличии } \\
\text { сбытового онлайн- } \\
\text { сервиса }\end{array}$ \\
\hline
\end{tabular}

Обсуждение. Критический анализ существующих методик показал, что ни одна из представленных не учитывает применения цифрового механизма взаимодействия между участниками рынка и классического взаимодействия Offline торговли. Для углубления анализа развития рынка торговых услуг авторы сформировали методику оценки этого рынка с точки зрения классического подхода с учетом собственных показателей, необходимых для оценки экономической ситуации и современных тенденций развития, а также с точки зрения происходящих цифровых трансформаций и взаимозависимости деятельности участников рынка.

Полученные результаты. В целях изучения развития рынка торговых услуг в процессе цифровой трансформации предпринята попытка разработки комплексной методики оценки с выявлением основных направлений и анализом информации. Здесь была учтены основные элементы методологии научного исследования, такие как цель, задачи, принципы, комплекс показателей, методы и определенный перечень инструментов (рис. 1).

Цель предлагаемой методики состоит в получении достоверных данных о процессах развития рынка торговых услуг (объекта наблюдения), включая результаты исследования процесса цифровой трансформации. Достижение предусмотренной настоящей методикой цели позволит получить необходимые данные для формирования и выявления исчерпывающих сведений о состоянии и направлении развития рынка торговых услуг. Опираясь на полученные данные, можно сформировать ряд выводов, выявить «позитивные» и «негативные» оценочные суждения и сделать соответствующее заключение, представляющее собой рекомендательный набор определенных мер по устранению «негативного» воздействия. 


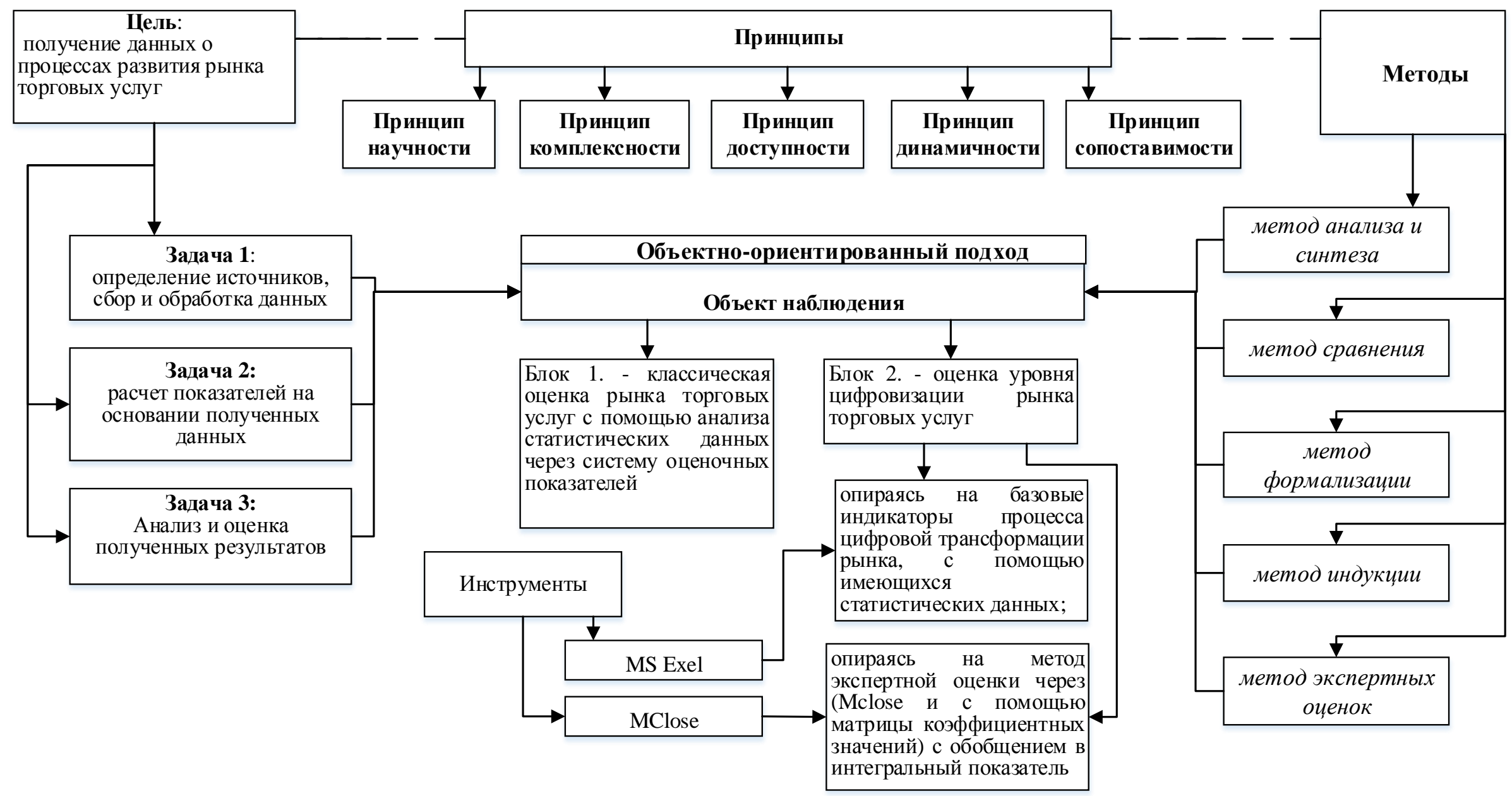

Рисунок 1. Последовательность оценки рынка торговых услуг в условиях цифровой трансформации [составлено автором] Figure 1. The sequence of evaluation of the trading services market in the context of digital transformation [compiled by the author] 
Основными задачами для реализации поставленной цели служат:

- определение достоверных источников, сбор и обработка необходимых данных в соответствии с установленными в настоящей методике целевыми результатами и комплексом показателей;

- расчет определенных методикой комплексов показателей на основании полученных данных с применением детерминированного автором инструментария;

- анализ полученных результатов, базирующихся на комплексах показателей, и их оценка.

Основными инструментами, применяемыми для получения результатов проводимого исследования, выступили вычислительные программные средства, в составе которых представлены: программа для работы с электронными таблицами и моделированием визуализации результатов Microsoft Excel; алгоритм Mclose (Свидетельство о гос. регистрации программы для ЭВМ № 2018611886).

Классическая оценка рынка торговых услуг с помощью статистических данных представляет собой комплексный анализ основных категорий рынка - спроса, предложения и инфраструктуры. Данный блок имеет важное значение, поскольку с его помощью мы можем продемонстрировать основные закономерности и отобразить общее состояние рынка торговых услуг. Здесь использованы оценочные показатели, которые отражают наиболее существенные параметры изучаемых категорий рынка торговых услуг, и предложено их экономическое обоснование.

Оценка уровня цифровизации рынка торговых услуг предполагает анализ процессов цифровой трансформации, который состоит из двух этапов, в том числе изучения показателей цифровизации рынка торговых услуг (рис. 2.).

На блок-схеме развития рынка торговых услуг с учетом процессов цифровой трансформации отображены два основных направления, которые позволяют раскрыть состояние цифровой среды, проследить развитие Online процессов, сопровождающих основные бизнес-операции между участниками рынка, а также установить зависимость рынка и деятельности, осуществляемой на нем, от цифровизации. Первым направлением исследования цифровой трансформации является мониторинг основных индикаторов этого процесса на рынке торговых услуг, на основании чего исследователем может быть сделан вывод о состоянии цифровой среды рынка и развитии цифровых технологий по двум подгруппам показателей.

1 группа - показатели, характеризующие уровень цифровизации населения, являющегося источником спроса, существующего на рынке торговых услуг.

2 группа - показатели, характеризующие уровень цифровизации торговых агентов, олицетворяющих предложение, существующее на рынке торговых услуг.

Сопоставление данных показателей демонстрирует готовность принятия цифровых технологий основными участниками рынка, а также недостаток или избыток цифровизации. Анализ необходим для определения мер по управлению процессами цифровизации на рынке, позволяющими контролировать их и вносить необходимые коррективы для увеличения полезного эффекта от функционирования данного рынка.

Вторым направлением, имеющим особое значение в представленной авторской методике, является оценка цифровой трансформации рынка торговых услуг, компонентов ее воздействия и уровня интеграции в деятельность торговых агентов на основе экспертного метода. 
Торговля, сервис, индустрия питания. 2021. Том 1, № 4

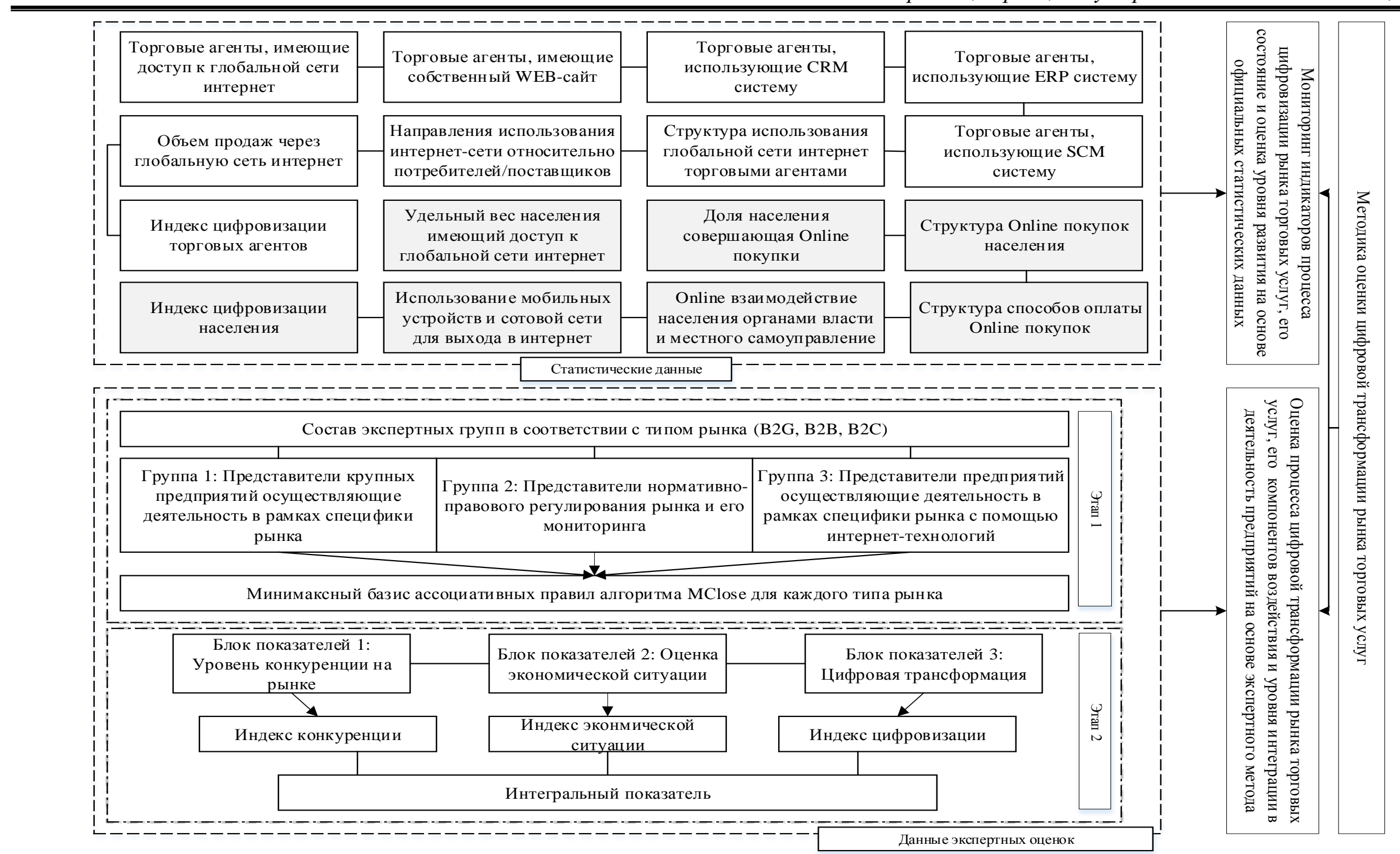

Рисунок 2. Методика оценки развития рынка торговых услуг с учетом процессов цифровой трансформации

Figure 2. Methodology for assessing the development of the trade services market taking into account the processes of digital transformation 
Начальным этапом анализа стал расчет минимаксного базиса строгих ассоциативных правил для каждого типа рынка, что подразумевает создание матрицы с помощью программируемых серий вычислительных экспериментов алгоритма MClose с целью установления взаимозависимых связей и причинно-следственных ассоциативных правил для основных критериев рынка и процессов цифровой трансформации на нем. Следующий этап исследования процессов цифровой трансформации на рынке торговых услуг - расчет интегрального показателя через установленные индексы, рассчитанные исходя из данных матрицы экспертных групп. Матрицу данных предлагаем формировать на основе мнений членов экспертных групп о реальных процессах, протекающих на рынке торговых услуг за анализируемый период, посредством фиксации однозначных ответов (Утверждение \Отрицание) по заданным критериям. Полученная матрица содержит исходные данные для расчета интегрального показателя по формуле:

$$
J=\sqrt[3]{I_{k} \times I_{e} \times I_{d}}
$$

где $I_{k}$ - индекс конкуренции ; $I_{e}$ индекс экономической ситуации; $I_{d}$ - индекс цифровизации. Все индексы рассчитаны с помощью средней арифметической. Данный показатель имеет коэффициентное выражение, пороговые значения $-0 ; 1$. При $J=0$ на рынке наблюдается негативная обстановка, отсутствует процесс цифровой трансформации. При $J=1$ рынок оценивается позитивно, с активно развивающейся цифровизацией.

Выводы и дискуссионные вопросы. Авторский взгляд на методику оценки рынка основан на мониторинге статистических данных, приведенных за анализируемый период. Основная задача, стоящая перед исследователем, - выявление основных тенденций и закономерностей, сложившихся на рынке. При этом особенность методики заключена в возможности учета результатов цифровой трансформации, поскольку от динамики развития цифровой среды в процессах деятельности участников рынка зависит эффективность его развития и уровень отдачи. Для сферы торговли цифровизация имеет особое значение, поскольку применение таких инструментов снимает границы для торговых агентов в территориальном и затратно-производительном аспектах, что позволяет активно наращивать обороты и увеличивать приток денежных средств в страну. Развитие цифрового рынка торговых услуг позволяет расширять рамки сбыта, снимать ограничения доступности для потребителей по территориальному признаку. Кроме того, торговые агенты получают большой спектр дополнительных возможностей в виде упрощения собственной деятельности, обработки данных, мгновенного получения информации и других важных преимуществ, которые не только влияют на конкурентоспособность, но и приводят экономическую систему в равновесие, позволяя отслеживать любые структурные рыночные сдвиги. Этим обусловлена актуальность создания авторской методики оценки рынка торговых услуг.

\section{Библиографический список}

1. Ефремова, М. В. Оценка месторасположения торговых центров [Текст] / М. В. Ефремова, О. В. Чкалова // Экономический анализ: Теория и практика. - 2013. Сер. 13, вып. 316.- С. 13-17.

2. Вайл, П. Цифровая трансформация бизнеса [Текст] / П. Вайл, С. Ворнер // Harvard Business Review Press (USA). - 2019. - 296 c.

3. Куимов, В. В. Подходы к исследованию системы обслуживания покупателей [Текст] / В. В. Куимов, Л. Т. Смоленцева // Вестник Алтайской академии науки и права. - 2019. - №12. - C. 182-188. 
4. Марцулевич, Д. В. Оценка влияния фактора удобства использования сайта (юзабилити) н потребительскую удовлетворенность интернет-магазинов [Текст] / Д. В. Марцулевич // Вестник Научно-исследовательского центра корпоративного права, управления и венчурного инвестирования Сыктывкарского государственного университета. - 2017. - № 4. - С. 77-89.

5. Суслова, Ю. Ю. Теоретические и методические подходы к изучению рыночного потенциала и его емкости [Текст] / Ю. Ю. Суслова, Д. А. Григорьев // Проблемы современной экономики. - 2014. - Сер. 2, вып. 50. - С. 234-237.

6. Роуз, М. Переосмысление методов исследований для развития ресурсной концепции: выявления источников устойчивых конкурентных преимуществ [Текст] / М. Роуз, У. Даелленбах // Российский журнал менеджмента. - 2003. - № 2. - С. 12-16.

7. Терещенко, Н. Н. Методологические подходы к экономической диагностике развития потребительского рынка [Текст] / Н. Н. Терещенко // Проблемы современной экономики. - 2008. - № 3. - С. 608-611.

8. Управление и организация в сфере услуг. Теория и практика [Текст] / К. Хаксевер, Б. Рендер, Р. Рассел, Р. Мердик. - Санкт-Петербург : Питер, 2002. - 118 с.

9. Цивлин, А. П. Система конкурентоспособность - качество-клиент в эпоху цифровых технологий [Текст] / А. П. Цивлин, В. В. Герасименко // Аудит и финансовый анализ. - 2017. - № 3-4. - С. 350-354.

10. Шнорр, Ж.П. Состояние и развитие торговли территории в условиях глобализации: теория, методология, практика: автореф. дис. ... д-ра экон. наук : 08.00.05 [Текст] / Шнорр Жанна Павловна; Сиб. федер. ун-т. - Красноярск, 2015. - 41 с.

\section{References}

1. Efremova, M. V., Chkalova O. V. (2013). Assessment of the location of shopping centers. Economic Analysis: Theory and Practice. 13(316). 13-17.

2. Haksever, K., Render, B., Russell, R. \& Murdick, R. (2002). Management and organization in the service sector. Theory and practice. St. Petersburg : Piter. $118 \mathrm{p}$.

3. Kuimov, V. V., Smolentseva L. T. (2019). Approaches to the study of the customer service system. Bulletin of the Altai Academy of Science and Law. 12. 182-188.

4. Martsulevich, D. V. (2017). Assessment of the impact of the site usability factor on consumer satisfaction of online stores. Bulletin of the Research Center of Corporate Law, Management and Venture Investment of Syktyvkar State University. 4. 77-89.

5. Rose, M., Daellenbach, U. (2003). Rethinking research methods for the development of the resource concept: identifying sources of sustainable competitive advantages. Russian Journal of Management. 2. 12-16.

6. Schnorr, Zh. P. (2015). The state and development of trade of the territory in the conditions of globalization: theory, methodology, practice : abstract of the dissertation for the degree of doctor of economics. Krasnoyarsk. 41 p.

7. Suslova, Yu. Yu. Grigoriev D. A. (2014). Theoretical and methodological approaches to the study of market potential and capacitance. Problems of Modern Economy. 2(50). 234-237.

8. Tereshchenko, N. N. (2008). Methodological approaches to economic diagnostics of consumer market development. Problems of the modern economy. 3. 608-611.

9. Tsivlin, A. P., Gerasimenko, V. V. (2017). System competitiveness-qualitycustomer in the era of digital technologies. Audit and financial analysis. 3-4. 350-354.

10. Weill, P., Woerner S. (2019). Digital transformation of business. Harvard Business Review Press( USA). 296 p. 